the schedules of procedures suggested by the provident societies. The guidelines and schedules were produced in 1989, and data collected by the commission show a wide variation in charges before 1989 and a convergence thereafter. In March 1989, for instance, surgeons' charges for a coronary bypass graft operation varied from $£ 175$ to $£ 4000$, with $£ 1500$ being levied on 11 occasions and $£ 1600$ on nine occasions. In March 1992 surgeons charged $£ 2000$ on 108 occasions, $£ 1950$ on 11 occasions, and $£ 2200$ on 10 occasions. The maximum suggested by the British United Provident Association was $£ 2000 ; 56 \%$ of surgeons charged that price, and $46 \%$ of anaesthetists charged $£ 825$, the maximum price suggested for them.

The case has been made that the guidelines have a strong impact on the price, and the BMA accepts that a complex monopoly exists within the definitions used by the com- mission. The BMA does not accept, however, that this impact is not in the public interest; it believes that patients should be making their choice on grounds of quality rather than cost. For most economists it is an article of faith that impediments to a free market are a bad thing and that the commission should take some action. The remedies it is considering include prohibiting the BMA from publishing its guidelines and prohibiting insurers from reimbursing claims according to a schedule of procedures. Responses must be in by 4 August, and a final report will be produced probably early next year. Whatever happens, private medicine will remain a long way from being a perfect market, although patients will benefit the closer we come to one.

RICHARD SMITH Editor

\title{
The new information management and technology strategy of the NHS
}

\section{Person centred}

In the NHS, information technology has so far been perceived mainly as a management tool of little clinical relevance. Professional concern that inappropriate computerisation may harm patient care partly explains this, but the main reason is that NHS policies have given much higher priority to investment in systems for management and administration. By contrast, the new information management and technology (IM\&T) strategy for the NHS in England is "person centred," and patients should benefit directly. ${ }^{1}$ As the strategy is realised the information required for management will increasingly come from clinical computer systems. Because it sets clinical objectives for information technology in the NHS the strategy is to be welcomed.

The new strategy is described in more than 40 separate publications, although no single clear statement of it appears. The handbook for the specialists in information management and technology provides most details. ${ }^{2}$ The strategy's goal is "better health for the nation" achieved by "supporting care and communication through IM\&T." Five principles form the basis of the strategy: information should be person based; systems should be integrated; management information should be derived from operational clinical systems; data should be secure and confidential; and data should be shared across the NHS. To help achieve the strategy there will be facilitating projects (including the integrated clinical work station project), the development of an infrastructure for IM\&T (including administrative registers and NHS wide networking), central mechanisms for approval of contracts for IM\&T worth more than $f 1 \mathrm{~m}$, and a programme of training. Development of the coding and classification systems (Read codes) will continue through the clinical terms thesaurus. A new format, all digit NHS number will be introduced by 1995-a daunting and expensive task.

The strategy's success will be judged on how useful the new systems are found by health care professionals, particularly doctors and nurses: Mumford has argued that such users will use systems only if they help them achieve professional and personal goals. ${ }^{3}$ The design and evaluation of systems thus require the active participation of practising clinicians. The impact of systems on organisations, clinical process, and clinical outcome needs scientific evaluation. The imposition of systems designed remote from busy clinical environments is likely to be an expensive failure. We now need to build up substantial experience with clinical systems and this will take time.

Computers have many applications in medical records departments, laboratories, pharmacies, and nursing, radiology, and general practice. In addition, they facilitate interdepartmental communication. These aspects seem well covered by the new strategy. But clinicians also need systems for bibliographic retrieval, clinical research, medical education, and the assessment of health care technology and to help in making clinical decisions: this broader vision ${ }^{4}$ is missing. Similarly, links to research and development in clinical medicine and information technology that should be part of such a strategy are missing.

Will industry respond with the products, particularly clinical systems, that such a strategy needs? There is a danger that it is waiting for government money to be put into pilot systems. Industry itself should help define the new market and take a lead in innovative clinical products, with the collaboration of clinicians and researchers.

In all this it is important to acknowledge the world beyond the NHS. If medical data need communicating inside the NHS then they will also need communicating outside it, and the NHS does not need to reinvent standards that are emerging at a European and international level for information technology in health care. Similarly, the results of clinically oriented research and development in the European Community's programme on Advanced Information in Medicine could be usefully exploited.

Clinical Operational Research Unit

M S LEANING Principal research fellow

University College London

London WC1E 6BT

1 Information Management Group, National Health Service Management Executive, Department of Health. Getting better with information: IMETT strategy overview. London: NHSME, 1992.

2 Information Management Group, National Health Service Management Executive, Department of Health. Getting better with information: handbook for IMET specialists. London: NHSME, 1992.

3 Mumford E. Need for relevance in management information systems: what the NHS can learn from industry. $B M f$ 1992;302:1587-90.

4 Shortliffe EH, Perrault LE, Fagan LM, Wiederhold G, eds. Medical informatics. Computer applications in health care. Reading, Massachusetts: Addison-Wesley, 1990. 